\section{La política de una ausencia}

\section{Politics of an Absence}

José Santa Cruz

Universidad ARCIS, Santiago

josekmorfeo@yahoo.es

Resumen - La pregunta por la relación entre lo político y el arte implica pensar as condiciones operativas de los dispositivos de sentido (obras, acontecimientos, experiencias, discursos) en un contexto específico de su presente, con relación a tras áreas de la sociedad. Desde esta perspectiva, ensayaremos la articulación del problema de lo político como una figura ausente en el cine chileno actual, proponiendo una lectura desde las experiencias que Reinaldo Laddaga ha comprendido como las estéticas de la emergencia. Experiencias culturales y estéticas que generan comunidades artificiales y temporales, con el fin de edificar subjetividades colectivas; desarticulando lo que Jacques Rancière ha llamado: el estado de «arte por el arte» en el cine contemporáneo.

Palabras clave: lo político, cine chileno, autonomía, estéticas de la emergencia.

Abstract - The question about the relationship between the political issue and art, implies thinking about the operative conditions of the devices of senses (works, events, experiences, discourse) in an specific context of its present, regarding other areas of society. From this perspective, we will attempt an articulation of the political issue as an absent figure on the current Chilean cinema, proposing an analysis of the experiences that Reinaldo Laddaga have understood as the aesthetics of irruption. The cultural and aesthetics experiences create temporal and artificial communities, in order to build collective subjectivities; disarticulating what Jacques Rancière has called the status of «art for art's sake» in the contemporary cinema.

Keywords: Politic Issue, Chilean Cinema, Autonomy, Aesthetics of Irruption.
Crear una obra de arte, es tomar posición, se quiera o no, en relación a la división del trabajo y la estandarización de los comportamientos. Pues el modo de producción que el artista elige o inventa, genera relaciones con el mundo que le implican en el universo económico $[. .$.

¿Cómo articular una discusión de lo político en el estado actual del cine? Cuando éste ha reclamado con suficiencia su autonomía, ha desarrollado templos para su adoración, festividades y textos testigos de sus creencias, feligreses y profetas que nos hablan de su devenir y porvenir, un sistema de creencias que ha puesto entre paréntesis sus relaciones con lo social, con lo simbólico, cuando las masas ya no sueñan en 24 cuadros por segundo. ¿Cómo articular el problema de lo político en la escena local? Cuando todo está cooptado en la discusión de una industria que no deja réditos económicos suficientes y una imagen que debería ser portadora de un nosotros, fragmentado, doliente, esquizofrénico, pero al fin de cuentas un nosotros. Dónde subyace la pregunta fundamental, ¿cómo pensar a inicio del siglo XXI lo político «en» arte? cuando éste estuvo un siglo intentando administrar su autonomía para transformar las formas de lo social, desde Gustave Coubert y el artista como obrero hasta la neovanguardia y el artista como crítico cultural, pasando por el artista-productor del constructivismo ruso y el artista al-khimista ${ }^{1}$ de las formas del futuro en la vanguardia, por nombrar algunos, y en todos el fracaso de la crítica en las manos de su mercantilización e institucionalización.

En este texto nos proponemos pensar estas preguntas y, en dicho ejercicio, encontrar pistas de sus respuestas, pero prevenidos del eventual fracaso que esta disposición conlleva, en la medida en que las relaciones entre lo político y el cine -arte- siempre son móviles y en proceso de re-configuración, por lo que, sus formas y límites se van escapando en cuanto los conceptos los van trayendo. Además también contamos con la sospecha de que la articulación de lo político, que expondremos en este texto, es una ausencia en la escena local, lo cual no implica la posibilidad de otras configuraciones. Un vacío que ha sido invisibilizado por las necesidades del campo del cine, el cual al mismo tiempo que desea su autonomía económica debe administrar su dependencia a las herramientas estatales y, con ello, negociar en su imagen las formas simbólicas de su institucionalización.

Desde estos preceptos trabajaremos el artículo en tres partes, la primera, referirá al estado contemporáneo del arte y sus rendimientos políticos, o mejor dicho, sus posibilidades políticas en una sociedad que ha hecho del presente perpetuo su objetivo cultural. Para ello, ocuparemos el trabajo de Reinaldo Laddaga sobre la articulación de las estéticas de la emergencia. En la segunda, nos propondremos ver, cómo estas estéticas de la emergencia se pueden encarnar en el campo cinematográfico, intentando mellar esa autonomía del cine, que Jacques Rancière caracteriza como su principal trofeo producto de la «política de los autores» en los años ' 60 y ’ 70 . Finalmente, nos referiremos a esta articulación de lo político como ausencia en la escena local, pero intentando dar cuenta de algunas experiencias que podrían remitirnos a ella. De forma inaugural, y quizás como advertencia, consideraremos la necesidad de que lo cinematográfico expanda sus formas categoriales en relación a otros campos teóricos del arte, para dar cuenta de los procesos que el cine contemporáneo está 
padeciendo y abriendo. Este artículo trabajará con esa lógica, aunque se pueda caer en derivaciones o caminos confusos, pensamos que es fundamental para imaginar nuevos caminos reflexivos del hecho-cine.

\section{¿COMO PENSAR A INICIO DEL SIGLO XXI LO POLITICOC EN ARTE?}

Tras el agotamiento de la densidad crítica de la neovanguardia en las artes visuales, los anuncios del fin de la historia dialéctica y la puesta en cuestión del proyecto de la modernidad como progreso, la pregunta por lo político en el arte se transformó en un terreno infértil, en la medida en que hubo un convencimiento de que el arte como laboratorio político -en la autoconciencia de sus operaciones representacionales- era una configuración que respondía a la búsqueda de unir el arte y la vida. Esta búsqueda había sido clausurada cuando la realidad se hizo estética, o como lo piensa Jean Baudrillard, cuando triunfó el simulacro por sobre la gravedad de la realidad de las cosas, la representación ya no representaba, todo intercambio era imposible.

No existe un equivalente para el mundo. En esto consiste precisamente su definición, o indefinición. Sin equivalente no hay doble, ni representación, ni espejo. Cualquier espejo seguirá formando parte del mundo. No hay sitio para el mundo y para su doble al mismo tiempo. Por lo tanto, no hay verificación posible del mundo, razón por la cual la realidad es una impostura. Sin verificación posible, el mundo es una ilusión fundamental (Baudrillard, 2000: 11).

Desde esta perspectiva, el trabajo del artista alemán Joseph Beuys que intentó borrar los límites entre el arte y la vida, para restablecer un equilibrio mítico del mundo, por ejemplo en I like america and america likes me (1974) -quizás su acción de arte más importante-. En esta obra vivió con un coyote dentro de la galería Rene Block en Nueva York-USA Beuys al establecer una relación sin mediaciones con la alteridad -el coyote como animal sagrado- donde su única barrera era una capa de fieltro y un bastón, critica las políticas estadounidenses con los pueblos indígenas norteamericanos. Esta no protección de la vida se configuró como una protección de lo social. El artista utiliza la capa de fieltro para taparse durante su recorrido entre el aeropuerto y la galería, para no observar las imágenes del país hacedor de imágenes y no pisar otro terreno que no sea el del aeropuerto y la galería. Beuys durmió en la paja destinada para el coyote, mientras éste durmió en las capas de fieltro y hacia el final de la acción abrazó al animal y esparció por la galería la paja donde éste durmió las tres noches y tres días que duró la intervención, acción ritual que nos permite identificar el chamanismo curativo que idealiza Beuys.

Otro ejemplo de lo anterior es el trabajo de la brasileña Lygia Clark, que buscaba que la obra estuviera determinada por problemas fisiológicos, como es el caso de Máscaras sensoriais (1967) En ella problematiza la visión como forma de acceso al mundo, mediante obras que se transforman en entidades biológicas, como los bichos. Se trata de formas escultóricas, que tenían la facultad de ser manipuladas por el público de modo que las formas de los objetos iban modificándose, quitándole el privilegio óptico a las obras de arte. Y también en la serie de acciones psicoterapéuticas, donde su intención fundamental sujeto y cuerpo. Ejemplo de esto, es Túnel (1973) realizada mientras era profesora de la Sorbona en París-Francia, acción que consistía en un tubo de tela de unos 50 metros de largo, en que los participantes ingresaban para administrar las sensaciones de claustrofobia y volver a padecer los esfuerzos del alumbramiento. Clark hacía cortes a lo largo del tubo por donde los participantes tenían su segundo nacimiento. Este tipo de proyectos de Clark, como los de Beuys, verán clausurados sus rendimientos críticos cuando caen bajo sospecha lo social y la realidad.

Contexto que le dará la bienvenida a lo que se denominó arte simulacional, por ejemplo, en la obra Puppy (1992) del artista norteamericano Jeffs Koons, donde la densidad de lo animal se transforma en un arreglo floral de doce metros de altura. Expuesto por primera vez en Schloss Arolsen en Alemania durante la Documenta IX, Puppy exalta la condición ornamental del arte contemporáneo al mismo tiempo que su condición de transitoriedad, ya que la obra está sujeta a los procesos biológicos de las flores. O la serie Natural History del artista británico Demian Hirst, en que expone animales diseccionados en grandes contenedores transparentes llenos de formalina. Por ejemplo, en This little piggy went to market, this little piggy stayed home (1996) rebana en dos un cerdo adulto y lo expone en dos contenedores. En este accionar quirúrgico existe una mecanización de la carne, de los fluidos, del cuerpo, negando su condición expresiva, vaciando la operación efímera del body art o las acciones de arte, el cuerpo no es un reducto sino una superficialidad, que encuentra su mayor rendimiento en la medida en que se vuelve estetizable en un eterno presente.

El desarrollo mundial de todas las culturas de los flujos, de la información, los medios, las nuevas tecnologías y lo virtual, ha dado lugar a un tiempo cada vez más estallado, no lineal y no unificado, incluso no direccional. [Éste tiempo estallado es] Un presente autosuficiente, autárquico, separado de su pasado, sin proyecto ni utopía, que corre el riesgo de entrañar una «destemporalización del tiempo» propia de esta forma sincrónica del mundo que suprime los «horizontes de espera» [...] (Buci-Gluksmann, 2006: 47-48).

Laddaga identifica una serie de proyecto que han desplazado esta lógica de destemporalización del arte, donde la materialidad de la obra es remplazada por la conjunción de acontecimientos y subjetividades en un tiempo y espacio específicos, que se sustentan en la carencia de un pensamiento estético onmipresente que organice el «todo», para generar espacios de intercambio estético, simbólico e ideológico que intervengan directamente en las condiciones materiales de comunidades, poniendo en el centro de la operación la colaboración:

[...] para iniciar o intensificar procesos abiertos de conversación (de improvisación) que involucren a no artistas durantes tiempos largos, en espacios definidos, donde la producción estética se asocie al despliegue de organizaciones destinadas a modificar estados de las cosas en tal o cual espacio, y que apunten a la constitución de «formas artificiales de vida social», modos experimentales de coexistencia (Laddaga, 2006: 21-22).

Proyectos que entiende en el concepto de estética de la emergencia, ya que irrumpen en contextos específicos y generan un quiebre del estado de las cosas. Una de las particularidades de estos proyectos es la multiplicidad de objetos, sucesos y resultados que traen consigo, desde filmes hasta caminatas urbanas, desde libros a sociedades de difusión, su objetivo no es la concreción de materialidades, sino generar un espacio de construcción de subjetividades. Un ejemplo de ello son los resultados del proyecto del artista chileno Alfredo Jaar en el pequeño pueblo maderero Skoghall en Suecia. The Skoghall Konsthall (2000), consistía en la construcción de un museo para el pueblo, el cual vive completamente de una 
gran fábrica productora de papel y que carecía de un espacio para el arte y las expresiones culturales. El museo fue construido en papel y diseñado por arquitectos suecos, en el cual se expondrían las obras de una serie de artistas visuales jóvenes de Estocolmo, Malmo y Gotemburgo. La cronología del museo es la siguiente, éste se inauguraría por el alcalde y en presencia de la comunidad local, estaría abierto durante veinticuatro horas para que la comunidad pudiese visitar la exposición y en la ceremonia de clausura sería quemado con todas las obras en su interior. La condición efímera de la obra pretendía visibilizar la con todas las obras en su interior. La condicion efimera

Lo que no tenía previsto el proyecto, fue lo que se generó en torno a la planificación, construcción y destrucción del museo de papel. La comunidad protagonizó un fuerte debate de la necesidad de tener un espacio de confluencia social, se organizó un grupo de amigos del museo que se oponía férreamente a su incineración, a pesar de que la estructura de papel no resistiría el duro invierno sueco. Gran parte de la comunidad se involucró en la pregunta ¿qué rol juega el arte para ellos?, lo cual es decir ¿qué dimensión política tiene el arte en la construcción simbólica de las comunidades? La quema del museo permitió un aceleramiento en la construcción de la subjetividad en el contexto de Skoghall, en la medida en que se puso el acento en la autorreflexión como comunidad, exponiendo sus carencias sociales y movilizando las intenciones de un grupo específico para transformar sus formas de sociabilización. Si bien, Jaar pretendía con esto hacer evidente la necesidad del arte contemporáneo en las sociedades actuales, una demostración de poder ante la crítica de la evaporación del arte (Michaud, 2007), lo fundamental para nosotros está en esta dimensión que expresábamos anteriormente, es decir, cómo confluye una nueva estrategia política de la relación entre arte y sociedad, a través de proyectos que apuntan a emerger en la articulación de subjetividades, espacios y necesidades ausentes.

La emergencia, para Laddaga, no es simplemente una irrupción sino la actividad e impacto de una serie de elementos que en esa acción generan una regularidad que sus elementos por separado no tendrían. Si bien tienen una temporalidad menor que un objeto estable, estas emergencias se comportan como torbellino en contexto específicos y generan a su alrededor una serie de sucesos imprevisibles anteriores a la irrupción, que dependerán a su alrededor una serie de sucesos imprevisibles anteriores a la irrupción, que dependerán un aprendizaje" (Laddaga: 288) para incrementar los procesos de democratización de las sociedades, a través de la renuncia de las lógicas representativas, para activar microesferas públicas experimentales, donde la colectividad recupere el espacio de lo común. En esta lógica, justamente el rechazo al objeto como unidad del sentido último y, por ende, sujeto a su comercialización y fetichización, no tiene que ver con la vaporización del arte, sino más bien expuesto como elemento transitorio, articulado en extensas redes de sentido y experiencia, re-significando su relación referencial, ya no como representación sino en tanto referencia existencial a procesos sociales que les posibilitaron su existencia.

Lo político entonces lo estamos entendiendo en la puesta en marcha de experiencias estéticas que posibiliten la elaboración de subjetividades y saberes. Sucesos que repiensan el proyecto de agrupaciones artísticas como Fluxus en la unión de arte y vida, en que se busca una paulatina y constante desmercantilización de los espacios sociales (Wallerstein en Laddaga, 2006: 200). Una de las diferencias fundamentales con los movimientos de los años '60 y '70 será que al convocar al arte en la vida, el arte no está entendiendo a ésta como un todo estable en el cual desembarcar (happening), por lo cual, los sujetos convocados tan sólo se entendían como elementos más de la obra, o un sistema en tanto su condición biológica (land art) o un sistema social (situacionismo). Contemporáneamente se piensa la vida como un espacio de colectivización que es necesario construir. Será por esto que la figura de la red se vuelve prolífica, la red social es una de las figuras constituyentes en el quehacer cotidiano actual: twitter o facebook (por nombrar las en boga mientras se escribe este artículo) parecieran trabajan sobre esta lógica de lo colectivo, pero carentes de cualquier densidad social, y en definitiva política, ya que funcionan tal cual vertederos de fragmentos de lo individual y lo íntimo. Carecen de la construcción de subjetividades, donde los individuos convocados son los que determinan las formas y direcciones de dichos espacios a través de procesos de aprendizaje, una colectivización entendida como tejido artificial y efímero, y no como la reunión de fragmentos que aún reclaman su estabilidad, en la figura del presente perpetuo (Buci-Glucksmann, 2006: 46-47). Es decir, lo colectivo no es visto acá como forma y horizonte de sentido en la organización social. Ahí radicarí la apuesta política frente a un estado contemporáneo de la cultura, en que la conexión, el flujo y las redes determinan la enajenación y sobredeterminación de lo individual, aunque pudiese sonar contradictorio.

\section{¿COMO ARTICULAR UNA DISCUSIÓN DE LO POLÍTICO EN EL ESTADO ACTUAL}

\section{DEL CINE?}

En los años '60 se generó un fuerte movimiento al interior del cine, que tenía que ver con extensos conflictos político-sociales alrededor del mundo. África, Latinoamérica y Asia proponían nuevos caminos de autodeterminación política, que en el caso del cine tenían que ver con las formas de imaginarse a sí mismos, es decir, cómo hacer confluir en la imagen cinemática un nosotros al mismo tiempo que se renunciaba a las formas de producción y discursos hegemónicos norteamericanos. En confluencia con esto se fue desarrollando lo que actualmente se denomina la «política de autores». En el seno de la producción europea y encabezada por la nouvelle vague, se instaló la necesidad de que el cine no sólo fuese el lugar de la cristalización de los sueños de las masas, sino también, un espacio de autorreflexión de lo cinematográfico como crítica política a las maquinarias totalitarias. Ambos procesos no eran fenómenos aislados sino en constante diálogo, ya que encontraban en la crítica de los modelos hegemónicos de producción cinematográfica, un lugar de intercambio estético. Por eso, comúnmente se puede leer a Glauber Rocha como parte de los procesos de la política de autores, cuando éste más bien refería a la construcción de una estética moderna ligada a los procesos sociales en Brasil.

Dentro de esto emergió lo que se ha tendido llamar el cine de vanguardia, es decir, aquel que apostaba por la densidad del discurso cinematográfico, expandiendo las posibilidades experimentales del lenguaje fílmico, que implicaron tres grandes búsquedas: 1) Poner en crisis la narrativa ficcional del cine para generar una contemplación de la «realidad desnuda», abierta al suceso y al azar en la imagen (en una relectura del neorrealismo) o en la carencia de conflictos centrales, en la fragmentación narrativa, en el privilegio de micro-conflictos situacionales, etc. 2) Asumir su condición de lenguaje y desde ahí escarbar las posibilidades de lo cinematográfico como discurso simbólico sobre la sociedad, relacionándose con otras disciplinas, privilegiadamente el teatro, las artes visuales y la danza. 3) Estrechar la relación entre cine y la realidad, poniendo en crisis los modelos de producción de estudio, como a su vez, sacando los filmes de las salas de cine, para pensar lo cinematográfico en su despliegue en el espacio. 
Dentro de este último punto, el más denso desde las posibilidades políticas del cine, podemos encontrar el desarrollo de estrategias de intervención social de Chris Marker con los cinetracts, propaganda cinematográfica, anónima y de corta duración, que se exhibía sin procesos de edición sonora ni visual. También al Grupo de los 5, que generó «la noche de las cámaras encendidas» en Buenos Aires-Argentina, donde filmaron casi una decen de piezas fílmica en una noche (100 minutos de metraje aproximadamente) ensayando no sólo con las formas del lenguaje, sino con estrategias alternativas de producción, para ser presentadas en un congreso cinematográfico al día siguiente en Santa Fe, Argentina, o las propias del Grupo Dziga Vertov, encabezado por Jean-Luc Godard:

Su modelo es la intervención sorpresiva, "guerrillera", que quieren llevar al cine las táctica de agitación callejera. Son años en que las estéticas políticas perseguían géneros y formas de exhibición alternativas, que debían acompañar la manifestación y propaganda.

La acción política proporcionaba así su modelo a la acción cultural, pero este modelo se implementaba sobre las huellas de una estética: la del happening [...]

La pregunta de cómo hacer actos con imágenes (cinematográficas o plásticas) era perfectamente pertinente respecto de lo que se pensaba que debía ser el arte. No se trataba de intensificar una dimensión performativa, sino que todo arte tendía a ser, en todo momento, performativo (Sarlo, 2001; 189-190).

Podemos decir que, el cine, por primera vez, se ponía al corriente con otras formas de arte, que en la puesta en crisis de sus formas comenzaba a pensar una dimensión política de sí mismo. Es decir, mientras el cine moderno se dispuso a complejizar y expandir los límites de lo cinematográfico, generando una puesta en cuestión de sus formas como lenguaje y de producción, abrió las puertas a una dimensión política de la imagen y del hecho cinematográfico en la consolidación de una política de autor.

No obstante, cuando los procesos sociales fueron perdiendo su efectividad transformadora durante la década de los '70, por culpa de dictaduras, procesos de democratización de las elites gobernantes, el aletargamiento de conflictos sociales (Primavera de Praga, Mayo del 68, la matanza de Tlatelolco, etc.), la realidad destruyó a la imagen cinematográfica como contenedora de la potencia transformadora de las masas y, más aún, en su imposibilidad de sostener ese futuro que debía anunciar en el presente. La secuencia de la muerte del camarógrafo argentino Leonardo Henriksen en la Batalla de Chile (1975) de Patricio Guzmán que registrando el intento de golpe de estado conocido como «el tacnazo» (dos meses antes del golpe militar del 11 de septiembre de 1973) filmó el disparo de un soldado que le produjo su muerte. Quizás la secuencia más emblemática del anuncio de lo que vendría para la izquierda, no sólo chilena sino mundial. ¿Será éste el último intento del cine de anunciar el porvenir, cuando la catástrofe alcanza la imagen mientras aguardaba en el futuro? Justo ahí fue cuando la «política de autores» se transformó en el último recaudo de una posibilidad crítica:

Qué fue lo que ocurrió entre los años 1960-1970? Fue el momento de lo que se ha llamado política de los autores» en cine y es el momento en que en las artes tradicionales hubo forma radicales de cuestionamiento. El cine consolidó su estatuto artistico en el momento mismo en donde prácticamente en todos lados se llevaba adelante una denuncia del arte, una afirmación de que había que salir del mundo del arte. Entonces podemos decir que, paradójicamente, el estatuto mixto o impuro del cine finalmente lo dejó de lado de la pulsión de auto-supresión del arte que fue inherente a los programas vanguardistas (Rancière, 2009).
En esta consolidación de su estatuto artístico se centró su autonomía de la realidad, es decir, que desde ese punto se podía pensar autosuficiente como lenguaje y exponer su densidad auto-reflexiva. Como lo propone Rancière, el cine actualmente es el portador de una re-auratización de las formas estéticas; aquello que Walter Benjamin sospechaba había sido anulado por el propio mecanismo cinemático, fue re-significado desde la negación de su referencialidad y, más aún, poniendo bajo sospecha su condición de contenedor de los sueños de las masas. "El cine es hoy, en un sentido, el arte por el arte. [...] En este momento se podría decir que son los cineastas quienes encarnan la firma en el arte” (Ibid.).

Frente a este panorama, pensar una dimensión política del cine se vuelve complejo. Un ejemplo de ello es la autosuficiencia de su despliegue industrial y la sobre producción de filmes de autores, que no sólo reafirman su autonomía sino que además han desarrollado sistemas de validación y comercialización tan específicos como el modelo de los estudios sistemas de validación y comercialización tan específicos como el modelo de los estudios
que habían criticado. Será esa complejidad la que nos impulsa a establecer conexiones con otras áreas teóricas del arte, que nos den herramientas para poner en crisis ese proyecto de autonomía. Es por ello que se hace pertinente volver al texto de Laddaga y hacernos de la lectura que propone de la construcción del filme La commune (Paris, 1871) [La comuna (París, 1871)] (2000) de Peter Watkins, cineasta que participó en los procesos vanguardistas antes descritos y que ha sido el más preclaro de los cineastas en repensar dichas estrategias en el contexto contemporáneo.

En 1999 a las afueras de París en una fábrica abandonada, donde antiguamente se encontraban las instalaciones de los estudios de Georges Méliès, se grabó La commune (Paris, 1871) filme que tenía por objeto reconstruir la sucesos históricos de la comuna parisina de 1871. Tras la derrota de Luis Bonaparte en la guerra franco-prusiana y la ocupación de París, las organizaciones populares (communards) de la capital se revelaron y generaron un autogobierno, rechazando la ocupación prusiana y el gobierno liberal democrático de L. Adolphe Thiers francés -el cual firmó el armisticio con Guillermo I de Prusia- Gobierno que tenía por objeto la atomización de las organizaciones populares en toda Francia, este levantamiento armado y de autonomía popular ocurrió entre el 26 de marzo hasta el 28 de mayo, cuando aproximadamente 180.000 soldados asediaron la ciudad hasta derrotar la última de las barricadas de los communards.

A diferencia de otros filmes históricos similares, citemos por ejemplo, La révolution française [La revolución francesa] (1989) de Robert Enrico y Richard T. Heffron; The Last Emperor [El último emperador] (1987) de Bernardo Bertolucci o Ellos se atrevieron: La revolución rusa de 1917 (2007) del Grupo Contraimagen. El filme de Watkins desarrolló un particular proceso de producción, que convocó, por diferentes medios, a los vecinos de París a participar del filme como parte de su elenco. 220 de éstos trabajaron durante varios meses junto a historiadores y el grupo de producción, para perfilar cada uno de los personajes de los vecinos, los cuales debían representar medianamente a sus semejantes históricos, por ende, los personajes conservadores fueron reclutados dentro de esos sectores sociales, los provincianos de la misma forma, etc. Además se incorporaría un importante grupo de afrodescendientes e inmigrantes africanos. Ahora bien, ésta estrategia no dista mucho de las realizadas por la estética neorrealista, si no fuera por llevar al extremo la lógica de colectivización.

El proceso de grabación duró una semana y la operación fundamental del filme estará en que los acontecimientos tenían que ser impulsados obligatoriamente por los 220 vecinos, no habría un guión que los condujera ni un director que sancionara previamente si las acciones 
ejecutadas eran correctas o no porque la idea era llegar a objetivos específicos durante la grabación, pero las formas eran aleatorias. Producto de esta lógica un grupo decide organizar una pequeña célula informativa, entregando panfletos y además una especie de cana de televisión. Éstos obligarán a uno de los camarógrafos a que los siga, mientras reportean los sucesos que se van ocurriendo, asambleas, reuniones, enfrentamientos, etc. De alguna forma las cinco horas y media del filme (dividido en tres partes) están mediadas por este grupo y son un hilo conductor que cristalizó varios conflictos interesantes. Uno de éstos, sería la reproducción de las lógicas comunicacionales contemporáneas en la edificación y mediación de los conflictos sociales, a través de la imitación inconciente de las formas de lo televisivo. Por ejemplo, aquellos que oficiaban de reporteros constantemente interrumpían a los entrevistados e iban concluyendo y determinando sus respuestas.

Esto se desprende porque, en definitiva, la apuesta discursiva de La commune (Paris, 1871) más que reconstruir los sucesos históricos, se dispuso como un laboratorio del presente. Para imaginar cómo se podría desencadenar este plan de reconstrucción de los acontecimientos del otrora levantamiento popular en un «ahora». Sin duda, no hay que pensar esta operación de construcción como un «bien político» en sí mismo como ya lo advierte Paul Ardenne, a propósito de una multiplicidad de proyectos de arte participativos, que han sido conceptualizados por Nicolás Bourriaud en la estética relacional (2006), como aquellos que convoca a un desarrollo de intersubjetvidades:

No es que en estos proyectos no exista «relación» [intersubjetividad], pero ésta tiene sobre todo valor de pseudos, de relación que escenifica, pone en escena y representa antes de vivirla, además, en la mayoría de los casos, bajo la mirada benévola de los caciques (Ardenne, 2007: 136).

Más bien, hay que rescatar el objetivo detrás de esta operación, el de construcción de comunidades artificiales que en su ejercicio generan una producción de subjetvidad, y para ello es fundamental su colectivización.

De todas formas, el proceso de trabajo en La commune (Paris, 1871) se distancia radicalmente del modelo de producción del cine actual, sean grandes, medianas o pequeñas producciones, sean de talante comercial, autoral o un poco de ambos, sea documental o ficción, ya que la figura del director como «autor» funde sus límites con los procesos que van aconteciendo en el desarrollo de esa comunidad que construye el filme. Tanto es así, que muchos de los «actores» siguieron participando del proyecto en su edición y en su difusión, creando actividades para su exhibición y discusión, seminarios y coloquios en torno al filme por bastante tiempo. El rol de la comunidad será fundamental para la producción de esta película y que, a su vez, la diferenciará de otras producciones del mismo director inglés, como The Forgotten Faces [Los rostros olvidados] (1961) donde un grupo de actores no profesionales recreaban los sucesos de Hungría de 1956. Además será fundamental porque es parte de una perspectiva política de lo cinematográfico que está pensando Watkins, "instaurar un modo inmediato de expresión de la colectividad: una palabra común puede elevarse en su seno sin que haya necesidad de que haya que poner en operación un mecanismo representativo" (Rosanvallon en Laddaga, 2006: 163).

Para esto es fundamental el proceso de descentralización de los elementos constitutivos del filme, si bien Watkins es el director efectivo del filme éste intenta articularse como los generales de las fracciones anarquistas del ejercito republicano en la guerra civil española 1937-1939 -y no es abusivo pensarlo así tomando en cuenta el carácter marcadamente de izquierda de sus proyectos-, es decir, como un rol para una objetivo específico en un tiempo determinado, que deviene de las necesidades y decisiones de lo colectivo, y que a su vez, podría ser otro individuo. Tan fundamental será para Watkins que el proceso de colectivización no puede obviarse del ejercicio interpretativo de la dimensión discursiva del filme.

Nuestra forma puede verse en las largas secuencias y en la extensa duración de la película, que emergió del montaje. Lo significante, y creo muy importante de La comuna, es que los límites entre forma y proceso se funden, la forma hace posible que el proceso ocurra, pero sin el proceso la forma carece de sentido (Watkins en Laddaga: 166).

Lo colectivo estará también llevado a cabo en la visualidad, éste es un filme que podríamos decir, está abarrotado de gente, está abarrotado de subjetividades construyendo sociedad, extrañamente se ve a una persona sola, no sólo en las grandes asambleas, sino que generalmente se encuadran dos o tres personas, cosa que se replicará en el audio, las voces y los ruidos son múltiples, se superponen unos con otros o están como un rumor de fondo, es una subjetividad que también se construye colectivamente. El filme si bien pareciera ser una reflexión del pasado histórico francés, una especie de reactualización, está expuesto constantemente al presente político, social y cultural de Francia que irrumpe y articula una reflexión del estado contemporáneo, no una idea específica o un mensaje, sino un estado de la cuestión, un panorama o configuración simbólica del presente.

Lo particular de la operación realizada por Watkins, y que lo distancia de los filmes desarrollados en la vanguardia de los años ' 60 y' 70 , no es una pretendida inmediatez en la imagen, sino que se concentra en cómo los procesos cinematográficos se puedan modificar para conectarse con otros procesos sociales en la construcción de subjetividades. El filme deja de ser el centro de la operación de significación, para ser parte de un red de sentido que lo trasciende, que lo desplaza y en ello desvanece los límites de su autonomía. Este proyecto es parte de otros que:

[...] son constructivistas; se proponen la generación de «modos de vida social artificial», lo que no significa que no se realicen a través de la interacción de personas reales: significa que sus puntos de partida son arreglos en apariencia -y desde la perspectiva de los saberes comunes en la situación que aparecen- improbables. Y que dan lugar al despligue a comunidades experimentales, en tanto tienen como punto de partida acciones voluntarias, que vienen a reorganizar los datos de la situación en que acontecen de maneras imprevisibles, y también en cuanto que a través de su despliegue se pretende averiguar cosas más generales respecto a las condiciones de vida social en el presente (Laddaga: 15 ).

¿Qué queremos decir con todo esto? ¿qué tiene que ver con el cine? ¿cómo esto podría proponer una dimensión de lo político? En la condición contemporánea del cine, lo político debería apuntar en tres direcciones interconectadas. 1) La puesta en crisis de la condición de «autor» heredada del cine moderno. 2) La puesta en crisis del filme como unidad autosuficiente. 3) La desmercantilización de la producción cinematográfica. Estas tres aristas apuntan a desarticular la autonomía del cine por el cine, y esto a través de la colectivización del horizonte de sentido del filme y la articulación del filme en procesos culturales de construcción de subjetividades más amplia al propio hecho-cine. En esta perspectiva el proyecto La commune (Paris, 1871) resulta ejemplar. 


\section{¿CÓMO ARTICULAR EL PROBLEMA DE LO POLÍTICO EN LA ESCENA LOCAL?}

Tres años después del filme de Waltkins, Chile recibe el estreno de Sub-terra (2003) de Marcelo Ferrari, anunciada como la mayor súper producción hasta ese momento en el cine local. Elemento que se transformó en uno de los pilares de su campaña publicitaria, que se conjugaba con otro, quizás igualmente significativo en su pretensión, referir a la identidad e historia de la comunidad de Lota, ciudad ubicada en la octava región de Chile, que concentró toda su economía en la extracción del carbón, hasta el cierre de la mina por falta de rentabilidad el año 1997. El guión del filme pretendía recuperar una serie de relatos del escritor local Baldomero Lillo, para articular una película en torno al amor de un minero y una profesora a finales del siglo XIX, cruzado por los conflictos sociales que se vivían en la ciudad a propósito de la explotación de la oligarquía chilena sobre la clase trabajadora. A primeras luces un empeño muy loable de parte de este equipo de producción cinematográfico, ahí donde la desmemoria se gesta como acto cotidiano, el cine vendría a "reponerla".

Pero deteniéndonos un poco más en el filme, empiezan a salir esas rugosidades propias del acontecer cinematográfico local, ¿por qué un filme que pretende reponer y referir a la identidad de una comunidad específica, no tiene ningún contacto «real» con dicha comunidad más que como telón de fondo para una historia de amor que eclipsa todos los conflictos sociales? No deja de ser insignificante la selección de su héroe, Francisco Reyes, eximio protagonista de historias de amor televisivas de la estación estatal que marcó la década de los '90. Cuán conservadora perspectiva material es la que propone Ferrari a inicios del siglo XXI, que ni siquiera pareciera haber hecho eco de La battaglia di Algeri [La batalla de Argelia] (1966) de Gillo Pontecorvo, que pone en primer plano el mundo árabe que Hollywood y Europa habían confiscado a su condición ornamental (Stam, 2002: 253-258). Cuantas similitudes tiene con las operaciones de construcción del menoscabado cineasta chileno-alemán José Bohr y sus pretensiones de edificar la identidad chilena en la figura del «roto chileno", que fue tan vehemente confiscado al olvido por «el nuevo cine chileno", en esa época donde todos los cines periféricos a la industria eran nuevos y el chileno «revolucionario» (Mouesca, 1988: 70-72).

Sub-terra de Ferrari jtiene la misma densidad de construcción que los relatos de Lillo o, para decirlo de otra forma, en los relatos de éste podemos encontrar esa distancia que la imagen cinemática tiene de la piel, del color negrusco que se impregna en las paredes, de los tiempos de espera en la cocinerías, etc.? ¿Se podría llegar a decir que el filme de Ferrari, roza si quiera la complejidad política de la «cuestión social» a la que se vio enfrentada Lillo? ¿existe algún riesgo en la apuesta de la superproducción chilena? Y este último hecho jya ciencia que estamos enfrentados, por un lado, a la exposición soberan a de la pretensión simbólica del dinero, por otro, a la escritura en un cuarto obrero? No es abusivo plantear que una película como Sub-terra, no es sino la cristalización de las formas simbólicas de su institucionalización, la construcción de una memoria sin conflicto, es decir sin presente, una memoria que se nos presenta frente a los ojos infértil y en technicolor. Pero ¿por qué hablar de este filme y no de otro? Dos elementos son significativos, el primero es la matriz popular de los conflictos que exponen, que nos permite relacionarla simbólicamente con La commune (Paris, 1871). El segundo, es en relación al epígrafe con el que iniciamos este texto "Crear una obra de arte, es tomar posición, se quiera o no, en relación a la división del trabajo y la estandarización de los comportamientos». ¿ No es ésta la dimensión política del arte? Despojándose de sus tensiones con la institución arte o cine ¿no es la conciencia y puesta en conflicto de esto lo que impediría la desarticulación de lo político? Más allá de que se pueda hacer análisis de filmes que cristalicen simbólicamente un período histórico y procesos sociales o, en su defecto, que nos permitan graficar ideas sobre lo político en la actualidad o el pasado.

Se hace evidente que ni siquiera hemos referido a los problemas que tratamos de instalar para pensar lo político en lo cinematográfico, es decir, minar la figura del autor, quebrar la idea del filme como unidad autosuficiente o la desmercantilización del hecho-cine, para la colectivización de subjetividades y construcción de comunidades de sentido. Como también se deja entrever que operaciones como las que hemos expuesto en Sub-terra podríamos extrapolarlas a tantos otros filmes, como Tierra del Fuego (2000) de Miguel Littin, Mi Mejor Enemigo (2005) de Alex Bowen, Fiestapatria (2007) de Luis R. Vera o Huacho (2009) de Alejandro Fernández, por nombrar algunos pocos filmes locales. A su vez, tampoco hemos querido plantearnos si este tipo de filmes podrían entrar en diálogo con los problemas formales y de sentido que suscita el cine contemporáneo en el gobierno de una imagen cinematográfica que está pensando su estatuto de imagen (Santa Cruz G., 2009). Tan sólo nos haremos la simple pregunta, ¿podemos encontrar un acontecimiento cinematográfico en la escena local, de cualquier característica, que esté pensando la densidad de lo político en el estado actual de la cultura?

Si bien al inicio advertíamos que este artículo plantearía la ausencia de lo político, lo cual seguimos identificando como la mayor característica de la escena local, consideramos que si un problema de lo político logra visibilizarse será en torno al Festival de cine social y antisocial-FECISO, evento cinematográfico que se ha llevado a cabo desde el año 2007 y que se desarrolla durante el mes de diciembre en las comunas La Pintana, La Granja y San Ramón de Santiago. En su sitio web, inmediatamente encontramos una rareza; su logo es una pequeña cámara digital de vigilancia. Fuera de la sublimación de los dispositivos tecnológicos propios del cine, la cámara de vigilancia es por sobre todo el modelo high tech del panóptico foucaultiano, la sospecha de la pretensión de los organizadores de salirse de las lógicas comunes se verán confirmadas con su carta de presentación.

Fomentar y difundir la creación artística que aborda temáticas de crítica social de toda especie.

Promover el espacio de las organizaciones sindicales, sociales, antisociales, independientes o autogestionadas y sus cuestionamientos del mundo social en relación con las tendencias contemporáneas de la cultura audiovisual.

Establecer la discusión en espacios públicos como La Pintana y La Granja que según los canales Establecer la discusion en espacios públicos como La Pintana y La Granja que segú
formales no son aptos para el debate de las temáticas sociales y antisociales.

Incluir a la población de estas comunas a participar de los debates y cuestionamientos sociales y antisociales $[\ldots .$.

Su disposición de generar espacios de exhibición para un importante corpus de filmes y proyectos audiovisuales que, por razones evidentemente políticas, son marginados o automarginados de los circuitos mercantiles de exhibición. Y asimismo incorporar a organizaciones o colectivos sindicales, sociales y «antisociales». Localizándose geográficamente en tres comunas pobres de Santiago, con un alto grado de segregación simbólica y material por parte de la elites económicas y políticas del país -grupos poblacionales que son convocados y visibilizados por la sociedad sólo en su condición de consumidores o delincuentes-. Son elementos que a primera vista marcan el carácter abiertamente político del proyecto, 
aunque lo que es político en la cuestión social no necesariamente es político en el cine o en el arte. Las transferencias no son inmediatas y las formas de diálogo tampoco lo son, perfectamente podríamos tener este evento y configurar un nicho más del panorama mercantil local. Lo que nos resulta interesante de este proyecto es un paulatino avance hacia formas de sociabilización -no colectivización- de lo cinematográfico.

Para esto identificaremos dos elementos que son los más característicos del evento: 1) La obligatoria presencia de los directores en la presentación de los filmes y la posterior charla con los asistentes a la proyección. 2) Una serie de foros sociales callejeros en que se convoca a los habitantes de las comunas a discutir (a propósito del cine y el audiovisual) una serie de problemáticas que cruzan su realidad social. Estas actividades conjugan la pretensión principal de los organizadores, reestablecer el diálogo entre cine y sociedad, desacralizando la figura del cineasta-creador, es decir «autor», convocándolos a la tierra a hablar con aquellos mortales que poco saben de cine, como a su vez lograr que los filmes catalicen un espacio de subjetivización en los individuos a través del diálogo y la discusión de ideas con otros individuos, es decir, el cine como excusa para recomponer el tejido social que fue atomizado durante los últimos veinte años.

Sin embargo, aún consideramos que esta experiencia está en proceso de desarrollo, ya que se sustenta en la idea de su constancia en el tiempo, tal cual los festivales de cine, lo que implica que su porvenir puede reconfigurarse infinitas veces. Aquí podemos encontrar un germen de aquello que consideramos la articulación política en el estado contemporáneo del arte. Principalmente porque se ha puesto en marcha una pregunta, aunque no resuelta aún por el evento: ¿cómo el cine puede re-habitar el espacio social fuera de los límites de éste como industria o proto-industria, sin caer en el ejercicio didáctico o el mero rendimiento simbólico, y al mismo tiempo poner en crisis su estatuto de autonomía que se ha consolidado en la «altermodernidad»? (Bourriaud, 2009). Para finalizar, y con ello responder lo anunciado en el título de este artículo, «la política de una ausencia» devela la configuración política y social en que se ha cosificado el hecho-cine en la escena local, que se podría señalar de la siguiente forma: para que el cine chileno se hubiese podido pensar en el estado contemporáneo tuvo que cimentar su total ausencia en lo social, ahí donde la realidad había destruido la imagen cinematográfica y en ese gesto asegurar el retorno al sueño de su industrialización o protegido en la ideología del «autor», es decir, cerrarse sobre sí mismo, encontrar la autonomía donde poder descansar en paz. Es decir, la política de una ausencia es el ejercicio material de su institucionalización simbólica.

\section{REFERENCIAS}

Ardenne, Paul. (2006). Un arte contextual: Creación artística en un medio urbano, en situación, de intervención, de participación. Trad. De Françoise Mallier. Murcia: Cendeac. Baudrillard, Jean. (2000). El intercambio imposible. Trad. De Alicia Martorell. Madrid: Cátedra.

Bourriaud, Nicolás. (2006). Estética Relacional. Trad. De Cecilia Becerro y Sergio Delgado. Buenos Aires: Adriana Hidalgo editora.

-. (2009) Radicante. Trad. Michèle Guillemont. Buenos Aires: Adriana Hidalgo editora.

-. (2009a) Formas de vida; El arte moderno y la invención de sí. Trad. De Carmen Rivera Parra. Murcia: Cendeac.

Buci-Glucksmann, Christine. (2006). Estética de lo efímero. Trad. Santiago E. Espinosa

\section{Madrid: Arena Libros.}

Festival de cine social y antisocial-FECISO. (2007). Obtenido el 31 de marzo del 2010 desde: $<\mathrm{http}: / / \mathrm{www}$. feciso.cl/>

Guasch, Anna María. (2007). El arte último del siglo XX; Del posminimalismo a lo multicultral. Madrid: Alianza Editorial.

Laddaga, Reinaldo. (2006). Estética de la emergencia. Buenos Aires: Adriana Hidalgo editora. Michaud, Yves. (2007). El arte en estado gaseoso. Trad. Laurence le Bouhellec. México D.F.: Fondo de Cultura Económica.

Mouesca, Jacqueline. (1988). Plano secuencia de la memoria de Chile; veinticinco años de cine chileno (1960-1985). Santiago: del Litoral.

Santa Cruz G., José M. (2009). Cine contemporáneo: la autoconciencia del simulacro. Obtenido desde: <http://www.centroestudiosvisuales.cl/html/senasResenas/JoseSantaCruz_abril2009.pdf >

Sarlo, Beatriz. (2001). La máquina cultural. La Habana: Fondo Editorial Casa de las Américas. Shohat, E. y Stam, R. (2002). Multiculturalismo, cine y medios de comunicación. Trad. Ignacio Rodríguez Sánchez. Barcelona: Paidós Ibérica.

Rancière, Jacques. (2005). La fábula cinematográfica. Trad. Carles Roche. Barcelona: Paidós Ibérica.

- (2009). Poéticas de lo contradictorio. Consultado entre el 29 de marzo y 4 de abril del 2010 desde: <http://salonkritik.net/08-09/2009/08/las_poeticas_contradictorias_d_1. php\#more>
Recepción: viernes 2 de octubre de 2009 Aceptación: martes 9 de diciembre de 2009 